\title{
The effects of the body mass index on the physical function and the quality of life in the elderly
}

Authors' Contribution: A Study Design

B Data Collection

C Statistical Analysis

D Data Interpretation

E Manuscript Preparation

F Literature Search

G Funds Collection

\author{
Raziye Şavkın ABCDEF, Gökhan Bayrak² ABCEF, Nihal Büker ABCDF \\ ${ }^{1}$ School of Physical Therapy and Rehabilitation, Pamukkale University, Denizli, Turkey \\ 2 Physiotherapy and Rehabilitation Department of Faculty of Health Sciences, \\ Alparslan University, Muş, Turkey
}

\section{abstract}

Background: As in all age groups, the prevalence of overweight and obesity is gradually increasing in the elderly. The aim of this study is to examine the effect of the body mass index (BMI) on the physical function and the overall quality of life in the elderly.

Material and methods:

265 community-dwelling older adults (131 women and 134 men) were included. BMI, grip strength (hand-held dynamometer), physical performance (Short Physical Performance Battery, SPPB) and overall quality of life (WHOQOL-BREF) were assessed.

Results: 265 older adults were divided into three groups: normal $(n=66)$, overweight $(n=116)$, obese $(n=83)$. SPPS and WHOQOL-BREF psychological health scores of the normal group were statistically significantly higher than in the obese group $(p \leq 0.005)$. The WHOQOL-BREF physical health score of the normal and the overweight groups was significantly higher than in the obese group $(p \leq 0.005)$. Grip strength, SPPB and WHOQOL-BREF physical health scores of older men in all groups were better than in women $(p \leq 0.005)$

Conclusions: BMI negatively affects the physical function, physical health and the psychological domain of the quality of life in the elderly. In order to avoid or limit the effects of disability secondary to obesity and promote healthy ageing, the elderly should be encouraged to increase their physical activity and maintain healthy weight.

Key words: body mass index, older adult, physical functional performance, quality of life, disability.

\section{article details}

Article statistics: Word count: 2,150; Tables: 3; Figures: 1; References: 28

Received: May 2020; Accepted: October 2020; Published: December 2020

Full-text PDF: http://www.balticsportscience.com

Copyright @ Gdansk University of Physical Education and Sport, Poland

Indexation: Celdes, Clarivate Analytics Emerging Sources Citation Index (ESCI), CNKI Scholar (China National Knowledge Infrastructure), CNPIEC, De Gruyter - IBR (International Bibliography of Reviews of Scholarly Literature in the Humanities and Social Sciences), De Gruyter - IBZ (International Bibliography of Periodical Literature in the Humanities and Social Sciences), DOAJ, EBSCO - Central \& Eastern European Academic Source, EBSCO - SPORTDiscus, EBSCO Discovery Service, Google Scholar, Index Copernicus, J-Gate, Naviga (Softweco, Primo Central (ExLibris), ProQuest - Family Health, ProQuest - Health \& Medical Complete, ProQuest - Illustrata: Health Sciences, ProQuest - Nursing \& Allied Health Source, Summon (Serials Solutions/ProQuest, TDOne (TDNet), Ulrich's Periodicals Directory/ulrichsweb, WorldCat (OCLC)

Funding: This research received no specific grant from any funding agency in the public, commercial, or not-for-profit sectors.

Conflict of interests:

Corresponding author: Authors have declared that no competing interest exists.

Raziye Şavkın, PT, PhD, School of Physical Therapy and Rehabilitation, 20070, Pamukkale University, Denizli, Turkey.; e-mail: raziyesavkin@hotmail.com; ORCID ID: 0000-0002-1636-4082

Open Access License:

This is an open access article distributed under the terms of the Creative Commons Attribution-Non-Commercial-NoDerivatives 4.0 International (https://creativecommons.org/licenses/by-nc-nd/4.0/), which permits use, distribution and reproduction in any medium, provided the original work is properly cited, the use is non-commercial and is otherwise in compliance with the license. 


\section{INTRODUCTION}

The population aged 65 years and older worldwide is increasing with developing health services, increasing health awareness and technological developments [1]. However, as in all age groups, the prevalence of overweight and obesity is gradually increasing in the elderly [2]. In a study investigating the prevalence of overweight and obesity of adults over 50 years old from 10 European countries, $60.3 \%$ of adults were overweight and $19.2 \%$ were obese [3]. Obesity is a significant changeable risk factor and contributor to increased morbidity and mortality due to cardiovascular diseases, diabetes, cancer and chronic diseases $[4,5]$.

Active life expectancy has increased in all individuals worldwide, especially in the obese and among females [6]. Although the increasing life expectancy is positive for humanity, low quality of life and presence of individual diseases or even the extent of comorbidities can negatively affect an individual's life. Maintaining a healthy weight is important for healthy aging [7]. The functionality of older adults is associated with many factors such as age, chronic diseases, medications, nutritional status, and body mass index (BMI). Elderly people with a $\mathrm{BMI} \geq 30 \mathrm{~kg} / \mathrm{m}^{2}$ are $60 \%$ more likely to experience functional decline than individuals with a normal weight [8]. Obese elders are at a higher risk for mobility and functional impairment due to obesity-related comorbid diseases [1,9], and their quality of life is significantly affected by the decrease in physical functions and limited mobility [10]. In view of the above, the aim of this study is to examine the effect of BMI on the physical function and the overall quality of life in the elderly.

\section{MATERIAL AND METHODS}

\section{STUDY DESIGN AND DATA SOURCE}

The elderly who applied to the outpatient orthopaedics clinic of the university hospital or who came to the hospital as a patient companion and agreed to participate in the study between the years of May 2019 and December 2019 were assessed. Totally, 450 patients were assessed for eligibility. 132 patients who did not meet the eligibility criteria were excluded from the study. Likewise, 53 elders were excluded because they did not want to continue evaluations $(n=17)$, felt excessive fatigue during evaluation $(n=4)$, or due to missing data $(n=32)$. Finally, 265 elderly participated in the study.

\section{PARTICIPANTS}

Two hundred and sixty-five community-dwelling older adults (131 women and 134) men were enrolled in this study. The inclusion criteria were as follows: age $\geq 65$, self-reported lack of difficulty walking for two blocks and climbing 10 steps and performing activities of daily living, ambulation independently or with an assistive device (crutches, canes etc.), a score of $\geq 25$ from the Mini-Mental State Examination test. The exclusion criteria were as follows: nursing home residence, concurrent pathologies that affect the ability to perform physical activity or perform everyday tasks (e.g., stroke history, cancer, extremity amputation). The study was approved by the Clinical Research and Ethics Committee of the authors' affiliated institution. Informed consent was obtained from all patients.

\section{MeAsurements}

The patients' demographic data (age, gender, education, dominant upper extremity, marital status, etc.) were recorded. The dominant hand was determined by asking the preferred hand in daily activities such as writing, eating and handling heavy objects. Physical functions (grip strength, chair stand, gait speed, and balance tests) and the quality of life (patient-reported) were evaluated. 
BMI was calculated from height and weight $\left(\mathrm{kg} / \mathrm{m}^{2}\right)$. BMI categorization was done according to the World Health Organization (WHO) standards: normal weight (18.5-24.99 $\mathrm{kg} / \mathrm{m}^{2}$ ), overweight $\left(25-29.99 \mathrm{~kg} / \mathrm{m}^{2}\right)$ and obese $\left(\geq 30 \mathrm{~kg} / \mathrm{m}^{2}\right)[11]$.

Grip strength was evaluated with a Jamar hand-held dynamometer. The measurement was performed when the person was sitting straight, with the upper arm in a neutral position and at $90^{\circ}$ flexion of the elbow. The forearm was held in a neutral position and the wrist at a 0 to $30^{\circ}$ extension. Measurements were performed bilaterally (dominant and nondominant). Three measurements were performed with one-min intervals and the mean of three measurements was calculated.

The Short Physical Performance Battery (SPPB) test is used as a predictive tool for possible disability, nursing home and hospital admission. It is a valid and objective tool for measuring the physical function in older persons, particularly muscle strength of lower extremities [12]. SPPB consists of three sets: a timed repeated chair sit-to-stand test, hierarchical assessment of standing balance, and eight-foot $(2.44 \mathrm{~m})$ walking speed at usual pace [13]. A SPPB score of less than 10 has been reported to predict all-cause mortality [12]. Compared to those who scored 10-12, those who scored 4-6 are 2.9-4.9 times more likely to have a mobility-related disability and 1.5-2.1 times higher than those who scored 7-9 [14]. SPPB score categories (0-3: very low physical function, 4-6: low physical function, 7-9: moderate physical function, 10-12: high physical function) according to the cut-points provided by Guralnik et al. in their original work [13].

The World Health Organization Quality of Life Instrument, Short Form (WHOQOL-BREF) is one of the most useful generic forms that provide a brief assessment of the quality of life. It comprises 2 items from the Overall Quality of Life and 4 major domains, which measure physical health (7 items), psychological health (6 item), social relationships (3 item), and environment domains (8 item). The range of the component scores is $0-100$, with higher scores reflecting a more favourable health status [15].

\section{STATISTICAL ANALYSIS}

The data was analysed using SPSS 24.0 (IBM Corp. Released 2016. IBM SPSS Statistics for Windows, Version 24.0. Armonk, NY: IBM Corp.) package program. Continuous variables are given as mean \pm standard deviation, median (minimum and maximum), and categorical variable values are presented as absolute numbers and percentages. Homogeneity of the variances among the groups was tested with Levene's test. All data were homogeneous $(\mathrm{p} \geq 0.05)$, and the Bonferroni method was used for multiple comparisons. Normality of data distribution was assessed by the Kolmogorov-Smirnov test. Spearman's Rank correlation coefficient was used to determine the relationships between the BMI and the physical function and the quality of life variables. The Mann-Whitney U test was used to compare the means by gender. Statistical significance was defined at the $5 \%(p \leq 0.05)$ level.

\section{RESULTS}

According to WHO classification, 265 older adults were divided into three groups: normal, overweight and obese (Fig. 1). The normal group consisted of 66 elders (mean age 70.48 years; 22 women and 44 men); the overweight group consisted of 116 elders (mean age 70.98 years; 55 women and 61 men), and the obese group consisted of 83 elders (mean age 69.80 years; 54 women and 29 men). $29.4 \%$ of the elderly had very low and low physical function (normal: $18.2 \%$, overweight: $31.1 \%$, obese: $36.1 \%$ ); $47.9 \%$ had moderate physical function (normal: $50 \%$, overweight: $46.6 \%$, obese: $48.2 \%$ ), and $22.6 \%$ had high physical function (normal: $31.8 \%$, overweight: $22.4 \%$, obese: $15.7 \%$ ) (Table 1 ). 
The comparisons of grip strength, SPPB and WHOQOL-BREF scores of the groups are shown in Table 2. SPPS and WHOQOL-BREF physical health and psychological health sores of the normal group were statistically significantly higher than in the obese group $(p \leq 0.05)$.The WHOQOL-BREF physical health score of the overweight group was significantly higher than in the obese group ( $\mathrm{p} \leq 0.05$ ). There was no statistically significant difference between the groups in dominant and non-dominant side grip strength and WHOQOL-BREF social relationships and environment scores $(\mathrm{p}<0.05)$.

The comparison of the physical function and the quality of life variables of the groups by gender are shown in Table 3. Grip strength, SPPB and WHOQOL-BREF physical health scores of the older men in all groups were better than those of women ( $p \leq 0.05)$. WHOQOLBREF psychological health and environment scores of the older men in the normal and the overweight group were better than those of women $(p \leq 0.05)$. The WHOQOL-BREF social relationships score of the older men in the overweight group was better than of the women $(\mathrm{p} \leq 0.05)$. In the obese group, WHOQOL-BREF psychological health, social relationships and environmental scores did not differ by gender $(p<0.05)$.

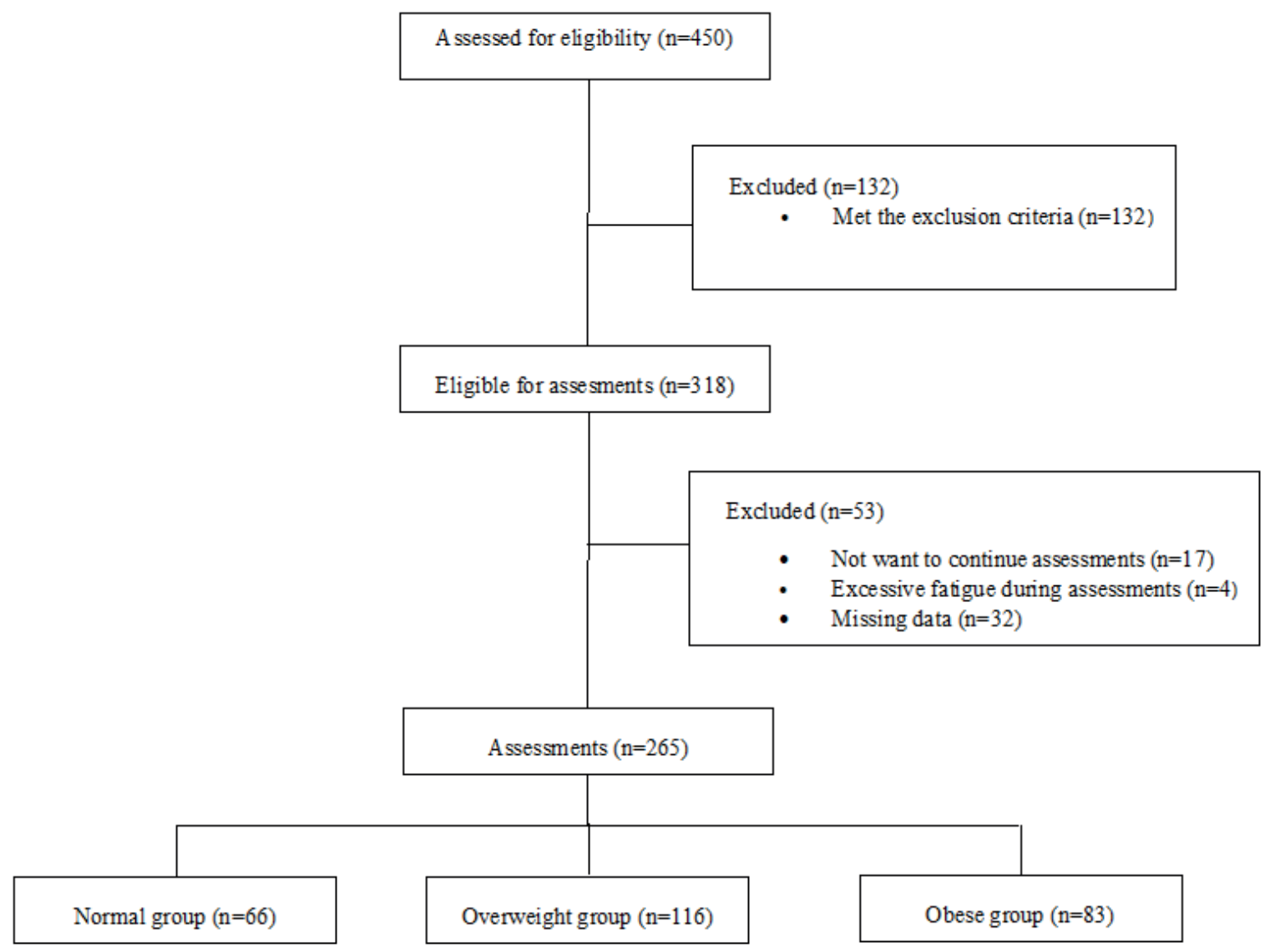


Table 1. Descriptive characteristics of participants

\begin{tabular}{|c|c|c|c|c|c|c|}
\hline \multirow{2}{*}{ Variables } & \multicolumn{2}{|c|}{ Normal $(n=66)$} & \multicolumn{2}{|c|}{ Overweight $(n=116)$} & \multicolumn{2}{|c|}{ Obese $(n=83)$} \\
\hline & Min-max & Mean \pm SD & Mean \pm SD & Mean $\pm S D$ & Mean \pm SD & Mean $\pm S D$ \\
\hline Age (y) & $65-87$ & $70.48 \pm 5.48$ & $65-87$ & $70.98 \pm 5.04$ & $65-80$ & $69.80 \pm 4.24$ \\
\hline \multirow[t]{2}{*}{ BMI $\left(\mathrm{kg} / \mathrm{m}^{2}\right)$} & $18.80-24.97$ & $22.81 \pm 1.72$ & $25.25-29.97$ & $27.60 \pm 1.34$ & $30.04-40.86$ & $33.72 \pm 2.73$ \\
\hline & $\mathrm{n}$ & $\%$ & $\mathrm{n}$ & $\%$ & $\mathrm{n}$ & $\%$ \\
\hline \multicolumn{7}{|l|}{ SPPB-summary scores } \\
\hline $0-3$ & 2 & 3.0 & 6 & 5.2 & 10 & 12.0 \\
\hline $4-6$ & 10 & 15.2 & 30 & 25.9 & 20 & 24.1 \\
\hline $7-9$ & 33 & 50.0 & 54 & 46.6 & 40 & 48.2 \\
\hline $10-12$ & 21 & 31.8 & 26 & 22.4 & 13 & 15.7 \\
\hline \multicolumn{7}{|l|}{ Dominant extremity } \\
\hline Right & 54 & 81.8 & 93 & 80.2 & 74 & 89.2 \\
\hline Left & 12 & 18.2 & 23 & 19.8 & 9 & 10.8 \\
\hline \multicolumn{7}{|l|}{ Gender } \\
\hline Female & 22 & 33.3 & 55 & 47.4 & 54 & 65.1 \\
\hline Male & 44 & 66.7 & 61 & 52.6 & 29 & 34.9 \\
\hline \multicolumn{7}{|l|}{ Education } \\
\hline Illiterate & 8 & 12.1 & 22 & 19.0 & 18 & 21.7 \\
\hline Elementary education & 28 & 42.4 & 68 & 58.6 & 47 & 56.6 \\
\hline Secondary education & 9 & 13.6 & 9 & 7.8 & 10 & 12.0 \\
\hline High school & 12 & 18.2 & 5 & 4.3 & 4 & 4.8 \\
\hline Associate degree & 3 & 4.5 & 3 & 2.6 & 1 & 1.2 \\
\hline Bachelor degree & 6 & 9.1 & 7 & 6.0 & 3 & 3.6 \\
\hline Master's degree & - & - & 2 & 1.7 & - & - \\
\hline \multicolumn{7}{|l|}{ Marital status } \\
\hline Single & 2 & 3.0 & - & - & - & - \\
\hline Married & 50 & 75.8 & 94 & 81 & 59 & 71.1 \\
\hline Widow & 14 & 21.2 & 22 & 19 & 24 & 28.9 \\
\hline
\end{tabular}

Table 2. Comparisons of grip strength, SPPB and WHOQOL-BREF scores of the groups

\begin{tabular}{|c|c|c|c|c|}
\hline \multirow{2}{*}{ Variables } & $\begin{array}{l}\text { Normal } \\
(n=66)\end{array}$ & $\begin{array}{c}\text { Overweight } \\
(n=116)\end{array}$ & $\begin{array}{l}\text { Obese } \\
(n=83)\end{array}$ & \multirow{2}{*}{$\mathrm{p}$} \\
\hline & Mean \pm SD & Mean \pm SD & Mean \pm SD & \\
\hline \multicolumn{5}{|l|}{ Grip strength } \\
\hline Dominant extremity & $29.40 \pm 13.28$ & $29.97 \pm 16.65$ & $25.58 \pm 13.3$ & 0.104 \\
\hline Non-dominant extremity & $26.15 \pm 12.86$ & $26.57 \pm 15.98$ & $22.91 \pm 13.06$ & 0.182 \\
\hline SPPB & $8.54 \pm 1.94$ & $7.76 \pm 2.22$ & $7.12 \pm 2.63$ & $0.001^{\mathrm{a}}$ \\
\hline \multicolumn{5}{|l|}{ WHOQOL-BREF } \\
\hline Physical health & $66.40 \pm 18.16$ & $65.02 \pm 15.60$ & $58.48 \pm 17.84$ & $0.007^{a, b}$ \\
\hline Psychological health & $67.88 \pm 14.27$ & $63.83 \pm 15.69$ & $61.29 \pm 15.60$ & $0.034^{a}$ \\
\hline Social relationships & $65.97 \pm 16.00$ & $63.50 \pm 17.59$ & $59.89 \pm 17.49$ & 0.093 \\
\hline Environment & $64.83 \pm 13.47$ & $63.82 \pm 15.26$ & $61.75 \pm 14.64$ & 0.414 \\
\hline
\end{tabular}

SPPB: Short Physical Performance Battery, WHOQOL-BREF: World Health Organization Quality of Life Instrument Short Form. ${ }^{\text {a }}$ normal vs. obese, ${ }^{\mathrm{b}}$ : overweight vs. obese 
Table 3. Comparison of the physical function and the quality of life variables of the groups by gender

\begin{tabular}{|c|c|c|c|c|c|c|c|c|c|}
\hline \multirow{3}{*}{ Variables } & \multicolumn{2}{|c|}{ Normal } & \multirow{3}{*}{$\mathrm{p}$} & \multicolumn{2}{|c|}{ Overweight } & \multicolumn{4}{|c|}{ Obese } \\
\hline & $\begin{array}{l}\text { Women } \\
(n=22)\end{array}$ & $\begin{array}{c}\text { Men } \\
(n=44)\end{array}$ & & $\begin{array}{l}\text { Women } \\
(n=55)\end{array}$ & $\begin{array}{c}\text { Men } \\
(n=61)\end{array}$ & $p$ & $\begin{array}{l}\text { Women } \\
(n=54)\end{array}$ & $\begin{array}{c}\text { Men } \\
(n=29)\end{array}$ & $p$ \\
\hline & Mean $\pm S D$ & Mean $\pm S D$ & & Mean $\pm S D$ & Mean $\pm S D$ & & Mean $\pm S D$ & Mean \pm SD & \\
\hline \multicolumn{10}{|l|}{ Grip strength } \\
\hline $\begin{array}{l}\text { Dominant } \\
\text { extremity }\end{array}$ & $23.99 \pm 8.18$ & $32.10 \pm 14.55$ & 0.005 & $21.42 \pm 9.73$ & $37.68 \pm 17.85$ & 0.000 & $20.90 \pm 11.06$ & $34.31 \pm 13.13$ & 0.000 \\
\hline $\begin{array}{l}\text { Non-dominant } \\
\text { extremity }\end{array}$ & $20.96 \pm 6.84$ & $28.74 \pm 14.37$ & 0.004 & $18.34 \pm 8.99$ & $33.99 \pm 17.28$ & 0.000 & $18.49 \pm 10.29$ & $31.15 \pm 13.81$ & 0.000 \\
\hline SPPB & $7.57 \pm 1.80$ & $9.00 \pm 1.84$ & 0.005 & $7.22 \pm 2.20$ & $8.24 \pm 2.15$ & 0.012 & $6.59 \pm 2.78$ & $8.10 \pm 2.04$ & 0.006 \\
\hline \multicolumn{10}{|l|}{ WHOQOL-BREF } \\
\hline Physical health & $58.44 \pm 17.13$ & $70.37 \pm 17.51$ & 0.011 & $60.00 \pm 17.22$ & $69.55 \pm 12.47$ & 0.001 & $54.83 \pm 17.44$ & $65.27 \pm 16.80$ & 0.010 \\
\hline $\begin{array}{l}\text { Psychological } \\
\text { health }\end{array}$ & $58.33 \pm 8.23$ & $72.65 \pm 14.31$ & 0.000 & $58.94 \pm 16.96$ & $68.24 \pm 13.09$ & 0.001 & $60.42 \pm 16.56$ & $62.93 \pm 13.74$ & 0.463 \\
\hline $\begin{array}{l}\text { Social } \\
\text { relationships }\end{array}$ & $63.26 \pm 13.95$ & $67.33 \pm 16.93$ & 0.304 & $59.62 \pm 20.20$ & $67.01 \pm 14.11$ & 0.026 & $61.11 \pm 18.81$ & $57.61 \pm 14.78$ & 0.355 \\
\hline Environment & $56.56 \pm 10.96$ & $69.06 \pm 12.74$ & 0.000 & $59.80 \pm 17.08$ & $67.44 \pm 12.47$ & 0.008 & $62.19 \pm 13.85$ & $60.92 \pm 16.23$ & 0.722 \\
\hline
\end{tabular}

\section{DISCUSSION}

The physical function, the quality of life physical and psychological health domains of obese elderly compared to normal elderly were poor. Furthermore, the quality of life physical health domain of overweight elders was better than of the obese ones. Grip strength, social relationships and environment domains of the quality of life were not affected by BMI. In all groups, grip strength, SPPB and the quality of life physical health domain of the older men were better than women. In the normal and overweight group, there was a gender difference in the quality of life psychological health, social relations and environmental domains, while the difference in the obese group disappeared.

Some researchers reported that the optimal BMI range for the elderly should be 25-29.9 $\mathrm{kg} / \mathrm{m}^{2}$ [16], with an increased risk of mortality in the elderly with a BMI <23 [16] or BMI $<25[17,18]$. However, in many studies up to now $[19,20]$, it has been reported that the WHO references are valid for "the elderly", so in our study, we used WHO standards in the BMI category.

Although the level of functional decline in the elderly varies, loss of muscle mass is a common finding in the elderly population [21]. Obesity can directly affect physical functions by a negative impact on the lower limb muscle structure and function [22]. Previous studies reported that high BMI is associated with poor functional outcomes in the elderly living in the community [7, 9, 22-24]. In our study, although there was a decrease in the physical function of overweight elderly compared to the normal group, no statistically significant difference was found. However, the physical function of obese elderly was significantly poor compared to the normal group. In addition, according to the SPPB classification, the $18.2 \%$ of the normal group had very low and low physical functions while this rate increased to $31.1 \%$ in overweight and almost doubled in obese elders (36.1\%). Conversely, 31.8\% of the normal group showed a high physical function, while this rate dramatically decreased in the overweight (22.4\%) and the obese (15.7\%). An increased BMI is associated with lower physical functionality in all age and gender groups [25]. Unsurprisingly, as supported by our study results, the decline in physical functions caused by obesity and obesity-related disabilities is an important issue that needs to be addressed as it may interfere with the independence and activities of daily life. 
Overweight and obesity is associated with poor health-related quality of life in the elderly $[7,10,26]$, but satisfaction with life is not related to BMI [10]. We evaluated the overall quality of life rather than the health-related quality of life. As a result, the quality of life physical health domain of the obese elderly was poorer than among the normal and overweight elderly. Furthermore, the quality of life psychological health domain of the obese elders was worse than among the normal ones. Although BMI affects the quality of life physical and psychological health, it is not effective on the social relationships and satisfaction with the environmental conditions. We think that this situation reflects positive cultural and religious attitudes toward aging.

Obesity is associated with increased disability and a poorer health status, but disability and self-rated health varies considerably by age and gender [27]. We observed a better physical function among men than among women in all groups, consistent with previous studies $[25,28]$. In terms of the quality of life, except for social relationships domain of the normal group, the normal and overweight group showed gender differences in favour of men in all domains. However, there was no gender difference in the obese group, except for the physical health domain score. The fact that the physical health domain of the men in all groups is higher than of the women may be due to their higher physical functions. Regular physical activity is a key component to maintaining muscle strength and preventing further injury. The elderly can be encouraged to do at least 30 minutes of moderate physical activity on most, if not every day of the week, to improve their physical function and overall quality of life.

The limitations of our study include the small number of participants and the different number of participants in the groups, not questioning the nutritional status of the elderly, and the absence of comorbidity questioning. The strengths of our study are that physical activity levels were verified with a valid and objective tool to measure physical function, especially lower extremity muscle strength, in elderly people, and that there was no difference in the average age between the groups.

\section{CONCLUSION}

The significantly increased life expectancy is one of humanity's greatest achievements, and the goal is not only to prolong life but also to improve it. As a result, although it differs by sex, increased BMI may negatively affect the physical function, physical health and psychological health in older adults. In order to avoid or limit the effects of disability secondary to obesity and promote healthy ageing, older people should be encouraged to increase their physical activity and maintain healthy weight.

\section{REFERENCES}

[1] Jensen GL, Hsiao PY. Obesity in older adults: relationship to functional limitation. Curr Opin Clin Nutr Metab Care 2010;13(1):46-51. https://doi.org/10.1097/MCO.0b013e32833309cf

[2] Vincent HK, Vincent KR, Lamb KM. Obesity and mobility disability in the older adult. Obes Rev 2010;11(8):568-579. https://doi.org/10.1111/j.1467-789X.2009.00703.x

[3] Peralta M, Ramos M, Lipert A, Martins J, Marques A. Prevalence and trends of overweight and obesity in older adults from 10 European countries from 2005 to 2013. Scand J Public Health 2018;46(5):522-529. https://doi. org/10.1177/1403494818764810

[4] Ahima RS, Lazar MA. The health risk of obesity-better metrics imperative. Science 2013;341(6148):856-858. https:// doi.org/ 10.1126/science.1241244

[5] Park S, Lee S, Hwang J, Kwon JW. The impact of weight misperception on health-related quality of life in Korean adults (KNHANES 2007-2014): a community-based cross-sectional study. BMJ Open 2017;7(6). https://doi.org/10.1136/ bmjopen-2017-016098

[6] Zhang YS, Saito Y, Crimmins EM. Changing impact of obesity on active life expectancy of older Americans. J Gerontol A Biol Sci Med Sci 2019;74(12):1944-1951. https://doi.org/10.1093/gerona/glz133 
[7] Herman KM, Hopman WM, Vandenkerkhof EG, Rosenberg MW. Physical activity, body mass index, and healthrelated quality of life in Canadian adults. Med Sci Sports Exerc 2012;44(4):625-636. https://doi.org/10.1249/ MSS.0b013e31823a90ae

[8] Schaap LA, Koster A, Visser M. Adiposity, muscle mass, and muscle strength in relation to functional decline in older persons. Epidemiol Rev 2013;35(1):51-65. https://doi.org/10.1093/epirev/mxs006

[9] Bahat G, Muratlı S, Ilhan B et al. Body mass index and functional status in community dwelling older Turkish males. Aging Male 2015;18(4):228-232. https://doi.org/10.3109/13685538.2015.1061493

[10] Wang L, Crawford JD, Reppermund S et al. Body mass index and waist circumference predict health-related quality of life, but not satisfaction with life, in the elderly. Qual Life Res 2018;27(10):2653-2665. https://doi.org/10.1007/ s11136-018-1904-6

[11] Organization WH. Obesity: preventing and managing the global epidemic: World Health Organization 2000(No.894).

[12] Pavasini R, Guralnik J, Brown JC et al. Short physical performance battery and all-cause mortality: systematic review and meta-analysis. BMC Med 2016;14(1):215. https://doi.org/10.1186/s12916-016-0763-7

[13] Guralnik JM, Simonsick EM, Ferrucci L et al. A short physical performance battery assessing lower extremity function: association with self-reported disability and prediction of mortality and nursing home admission. J Gerontol 1994;49(2):M85-M94. https://doi.org/10.1093/geronj/49.2.M85

[14] Guralnik JM, Ferrucci L, Pieper CF et al. Lower extremity function and subsequent disability: consistency across studies, predictive models, and value of gait speed alone compared with the short physical performance battery. J Gerontol A Biol Sci Med Sci 2000;55(4):M221-M231. https://doi.org/10.1093/gerona/55.4.M221

[15] von Steinbüchel N, Lischetzke T, Gurny M, Eid M. Assessing quality of life in older people: psychometric properties of the WHOQOL-BREF. Eur J Ageing 2006;3(2):116-122. https://doi.org/10.1007/s10433-006-0024-2

[16] Winter JE, MacInnis RJ, Wattanapenpaiboon N, Nowson CA. BMI and all-cause mortality in older adults: a metaanalysis. Am J Clin Nutr 2006;99(4):875-890. https://doi.org/10.3945/ajcn.113.068122

[17] Kvamme JM, Holmen J, Wilsgaard T, Florholmen J, Midthjell K, Jacobsen BK. Body mass index and mortality in elderly men and women: the Tromsø and HUNT studies. J Epidemiol Community Health 2012;66(7):611-617. http://dx.doi. org/10.1136/jech.2010.123232

[18] Babiarczyk B, Turbiarz A. Body Mass Index in elderly people-do the reference ranges matter? Prog Health Sci $2012 ; 2(1): 58$.

[19] Rambod M, Ghodsbin F, Moradi A. The association between body mass index and comorbidity, quality of life, and cognitive function in the elderly population. Int J Community Based Nurs Midwifery 2020;8(1):45. https://doi. org/10.30476/IJCBNM.2019.81677.0

[20] Crotti G, Gianfagna F, Bonaccio M et al. Body mass index and mortality in elderly subjects from the Moli-Sani study: A possible mediation by low-grade inflammation? Immunol Invest 2018;47(8):774-789. https://doi.org/10.1080/088 20139.2018.1538237

[21] Aksoy MK, Altan L, Karlıbel IA. Associations between handgrip strength and vitamin 25 (Oh) D levels in geriatric patients. Folia Med 2019;61(3):397-403. https://doi.org/10.3897/folmed.61.e39346

[22] De Stefano F, Zambon S, Giacometti L et al. Obesity, muscular strength, muscle composition and physical performance in an elderly population. J Nutr Health Aging 2015;19(7):785-791. https://doi.org/10.1007/s12603-015-0482-3

[23] Busetto L, Romanato G, Zambon S et al. The effects of weight changes after middle age on the rate of disability in an elderly population sample. J Am Geriatr Soc 2009;57(6):1015-1021. https://doi.org/10.1111/j.1532-5415.2009.02273.x

[24] Stenholm S, Alley D, Bandinelli S et al. The effect of obesity combined with low muscle strength on decline in mobility in older persons: results from the InCHIANTI study. Int J Obes 2009;33(6):635-644. https://doi.org/10.1038/ijo.2009.62

[25] Buttery AK, Du Y, Busch M et al. Changes in physical functioning among men and women aged 50-79 years in Germany: an analysis of National Health Interview and Examination Surveys, 1997-1999 and 2008-2011. BMC geriatrics 2016;16(1):205. https://doi.org/10.1186/s12877-016-0377-0

[26] Huang I, Frangakis C, Wu AW. The relationship of excess body weight and health-related quality of life: evidence from a population study in Taiwan. Int J Obes 2006;30(8):1250-1259. https://doi.org/10.1038/sj.ijo.0803250

[27] Imai K, Gregg EW, Chen YJ, Zhang P, De Rekeneire N, Williamson DF. The association of BMI with functional status and self-rated health in US adults. Obesity 2008;16(2):402-408. https://doi.org/10.1038/oby.2007.70

[28] Wahrendorf M, Reinhardt JD, Siegrist J. Relationships of disability with age among adults aged 50 to 85: evidence from the United States, England and continental Europe. PloS One 2013;8(8):e71893. https://doi.org/10.1371/ journal.pone.0071893 